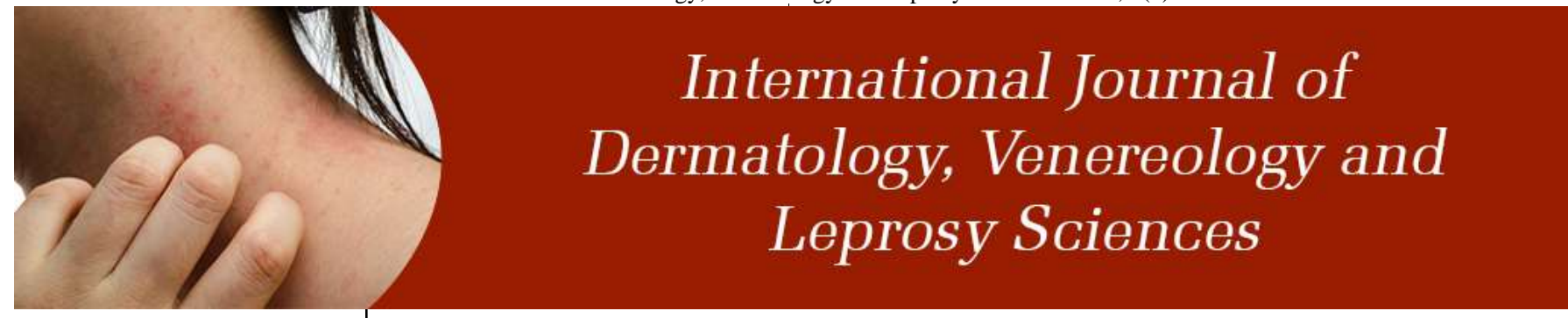

E-ISSN: 2664-942X P-ISSN: 2664-9411 www.dermatologypaper.com Derma 2021; 4(2): 34-38 Received: 23-06-2021 Accepted: 26-07-2021

Purnachandra Badabagni Associate Professor, Department of Dermatology, ESIC Medical College and Hospital, Hyderabad, Telangana, India

Jahnavi Sambangi Senior Resident, Department of Dermatology, ESIC Medical College and Hospital, Hyderabad, Telangana, India

Birudala Ramadevi Assistant Professor, Department of Dermatology, Kamineni Academy of Medica Sciences and Research Centre, LB Nagar, Hyderabad, Telangana, India
Corresponding Author: Purnachandra Badabagni Associate Professor, Department of Dermatology, ESIC Medical College and Hospital, Hyderabad, Telangana, India

\section{An observational study of co-relation of acne and metabolic syndrome}

\section{Purnachandra Badabagni, Jahnavi Sambangi and Birudala Ramadevi}

DOI: https://doi.org/10.33545/26649411.2021.v4.i2a.89

\begin{abstract}
Background: Acne vulgaris remains one of the commonest diseases of skin with chronic inflammatory dermatosis that affects 85 p.c of the adolescents and young adults globally. Acne is associated with greater psychological burden that include depression, anxiety, and low self-esteem. It is a multifactorial disease depending on genetic predisposition, follicular epidermal hyperproliferation, endocrine factors, the colonization and activity of Propionibacterium acnes, excess sebum production, inflammation, and environmental factors. Insulin resistance, dyslipidaemia, visceral adiposity, elevated blood pressure and chronic stress are several factors which constitute the metabolic syndrome

Aim \& Objectives: To analyse the relationship between Diabetes Mellitus, Dyslipidaemia, Hypertension, and Visceral Adiposity in Acne Vulgaris.

Material and Methods: A hospital based, analytical cross-sectional study was conducted among patients aged 14 years $\&$ above, irrespective of gender with acne vulgaris, irrespective of severity and attend the outpatient clinic of dermatology at a tertiary care hospital for a period of 12 months. Grading of acne was done according to Global Acne Grading System. Metabolic syndrome was diagnosed as per the criteria of the modified NCEP-ATP III.

Results: The patients with severe GAGS had high metabolic syndrome $(72.4 \%)$ when compared to those without metabolic syndrome (27.6\%), there exists an extreme statistically significant association between metabolic syndrome and GAGS (acne severity) with p-value $<0.001$.

Conclusion: HDL has high influence on acne vulgaris when compared to waist circumference, triglyceride, fasting blood sugar, and blood pressure.
\end{abstract}

Keywords: Acne, dyslipidemia, GAGS, HDL, metabolic syndrome

\section{Introduction}

Acne vulgaris (acne) is considered as one of the most commonly encountered dermatoses seen in clinical practice ${ }^{[1]}$. Acne vulgaris is the disease afflicting humanity and most commonly treated by physicians ${ }^{[2]}$. It is a pilosebaceous gland disease which usually affects people from puberty to early adulthood ${ }^{[3]}$. It is a common chronic inflammatory dermatosis that affects almost $85 \%$ of adolescents and young adults globally ${ }^{[4]}$. The prevalence of acne in adults is also rapidly increasing ${ }^{[5]}$. Reportedly, Acne vulgaris is affecting $2 / 3^{\text {rd }}$ of adults of age 18 and above ${ }^{[6]}$. The most severe forms of acne vulgaris occur in males more frequently, but in females the disease tends to be more persistent ${ }^{[7]}$. Acne is associated with certain psychological ailments that include depression, anxiety, and low self-esteem ${ }^{[8]}$.

Acne is characterized by seborrhoea, open \& closed comedones, pustules, erythematous papules, and in more severe cases it is characterised by nodules, deep pustules and occasionally pseudocysts ${ }^{[9]}$. Acne is multifactorial, depending on genetic predisposition, endocrine factors, hyperproliferation of follicular epidermis, excessive production of sebum, inflammation, colonization by Propionibacterium acnes, and environmental factors [9]. Certain factors have been proposed to cause precipitation or aggravation of acne which includes cosmetics, drugs, sunlight, and seasonal variation ${ }^{[9]}$. Stress is frequently implicated factor in aggrevating acne, however acne itself induces stress ${ }^{[8]}$. Recent studies suggest that diet plays a major role in the pathogenesis of acne ${ }^{[10]}$.

Presence of acne beyond the age of 25 years has been traditionally defined as Adult acne ${ }^{\text {[11] }}$ Adult acne is classified as persistent acne and late-onset acne. Adolescent acne persisting beyond the age of 25 years is known to be persistent adult acne and acne developing for the first time after the age of 25 years is known as late-onset adult acne ${ }^{[11]}$ 
In persistent acne, patients have lesions on most of the days and may also experience a premenstrual flare ${ }^{[11]}$. Late-onset acne is further subdivided into chin acne, which occurs around the chin and perioral area, it is of inflammatory origin, and premenstrual flares and sporadic acne which occurs suddenly in adulthood without any specific distinguishing features ${ }^{[11]}$.

Metabolic syndrome is defined as a constellation of interconnected biochemical, physiological, metabolic \& clinical factors with increased risk of cardiovascular disease \& type-2 Diabetes Mellitus ${ }^{[12]}$. Insulin resistance, visceral adiposity, dyslipidaemia, hypertension and chronic stress are the factors that constitute the syndrome ${ }^{[12]}$. Role of insulin in development of acne is associated with increased prevalence of acne in females with PCOS ${ }^{[12]}$. This study was mainly intended to analyse the correlation between diabetes mellitus, dyslipidaemia, hypertension \& visceral adiposity in acne vulgaris.

\section{Material and Methods}

A hospital based, analytical cross-sectional study was conducted among patients aged 14 years \& above, irrespective of gender with acne vulgaris, irrespective of severity and attend the outpatient clinic of dermatology in Employees' State Insurance Corporation Medical College and Hospital, Sanathnagar, Hyderabad, Telangana State. Patients with hirsutism, irregular menstrual cycles, known history of cardiovascular disorders, lipid metabolism disorders, hepatic disorders, drug intake that affect lipid metabolism, diabetes, renal disorder, harmful habit of smoking and those who were not willing to participate in the study were excluded. The study was conducted for a period of 12 months ( $1^{\text {st }}$ November 2020 to $30^{\text {th }}$ October 2021). A sample size was calculated considering acne vulgaris prevalence of 50 p.c, and an absolute precision of 10 p.c, the calculated sample size was $\geq 100$, in the present study about one hundred and three patients were included using systematic random sampling method. IEC approval was obtained. A written informed consent was obtained from the patients after explaining them clearly about the study details in their vernacular language. Patient data was recorded on a standardized proforma that include demographic data, detailed clinical history, past history, personal history, family history, comorbidities, and laboratory investigations. History of alcohol consumption or smoking everyday with $>180 \mathrm{ml}$ or $\geq 10$ cigarettes/beddi's was considered as having a habit of alcoholism or smoking. For laboratory investigations fasting blood sample was obtained under necessary precautions.

General examination and clinical examination of acne was done and grading was given according to Global Acne Grading System, each type of lesion was given a value depending on severity: no lesions $=0$, comedones $=1$, papules $=2$, pustules $=3$ and nodules $=4^{[2]}$. The score for each area (Local score) was calculated using the formula: Local score $=$ Factor $\mathrm{x}$ Grade $(0-4)$. The global score was the sum of local scores, and acne severity was graded using the global score (Table-1) ${ }^{[2]}$. In the present study a score of 118 was considered mild, 19-30 was considered moderate, 31-38 was considered severe and $\geq 39$ was considered very severe.

Metabolic syndrome was diagnosed as per the criteria of the modified National Cholesterol Education Program-Adult Treatment Panel-III (NCEP-ATP III). According to the
NCEP-ATP III definition, metabolic syndrome is present if three or more of the following five criteria are met: waist circumference over 40 inches (men) or 35 inches (women), blood pressure over $130 / 85 \mathrm{mmHg}$, fasting triglyceride (TG) level over $150 \mathrm{mg} / \mathrm{dl}$, fasting high-density lipoprotein (HDL) cholesterol level less than $40 \mathrm{mg} / \mathrm{dl}$ (men) or 50 $\mathrm{mg} / \mathrm{dl}$ (women) and fasting blood sugar over $100 \mathrm{mg} / \mathrm{dl}{ }^{[13]}$. Collected data was entered in Microsoft Excel-2019 and statistical analyses were performed using SPSS-23 (trial version) software. Data was presented as number (n) \& percentage for categorical data or mean \pm standard deviations for continuous data. The baseline characteristics were compared by chi-square test for categorical variables and one way ANOVA test was used to compare between $>2$ dependent groups. Pearson correlation test was also performed on continuous variables. In all the tests performed, a $p$-value less than or equal to 0.05 was considered statistically significant.

Table 1: The Global Acne Grading System

\begin{tabular}{|c|c|}
\hline Location & Factor \\
\hline Forehead & 2 \\
\hline Right cheek & 2 \\
\hline Left cheek & 2 \\
\hline Nose & 1 \\
\hline Chin & 1 \\
\hline Chest and upper back & 3 \\
\hline
\end{tabular}

\section{Results}

This study was conducted among one hundred and three (103) patients who were in accordance with the inclusion criteria. Among them majority, 57.3 p.c were females and 42.7 p.c were males. The mean age of the acne vulgaris patients was $38.5 \pm 11.2$ years. Majority of the patients were above 25 years age group, had a mixed diet, and family history of acne (Table-2). The mean waist circumference of the patients was $35.0 \pm 3.80$ inches, the mean SBP of the patients was $124.6 \pm 12.18 \mathrm{~mm}$ of $\mathrm{Hg}$, the mean DBP of the patients was $82.7 \pm 11.06 \mathrm{~mm}$ of $\mathrm{Hg}$, the mean TG level of the patients was $102.5 \pm 26.68 \mathrm{mg} / \mathrm{dL}$, the mean HDL level of the patients was $44 . \overline{3} \pm 5.40 \mathrm{mg} / \mathrm{dL}$, and the mean FBS level of the patients was $119.5 \pm 27.71 \mathrm{mg} / \mathrm{dL}$ (Table-2). The overall metabolic syndrome was present among 52.4 p.c of the patients and absent among 47.6 p.c of the patients. A harmful habit of alcoholism and smoking were present among 14.6 p.c and 18.4 p.c of the patients respectively. According to the GAGS the mean score of the acne vulgaris patients in the present study was $21.4 \pm 9.29$ and the grading of GAGS was 43.7 p.c of the patients were graded as mild, 35.9 p.c of the patients were graded as moderate, 20.4 p.c of the patients were graded as severe, and no patient was graded very severe. (Table-2).

Among the patients with metabolic syndrome the GAGS severity grading was increasing when compared those do not have metabolic syndrome, there exists an extreme statistically significant association between metabolic syndrome and GAGS (acne severity grading) with p-value $<0.001$. As the age increases there was an increase in the severity grade of GAGS, even though there was statistically significant association between age and GAGS (acne severity grading). The severity grading of GAGS was increasing among females when compared to males. Among the patients with severe GAGS, the family history of acne was high $(23.6 \%)$ when compared to those without family 
history of acne $(12.9 \%)$, there was no statistically significant association between family history of acne and GAGS (acne severity). Other variables like diet, history of alcoholism and smoking had no association with the severity of acne vulagris. (Table-3).

Among the metabolic syndrome variables that included waist circumference (WC), blood pressure, triglyceride levels (TG), high density lipoprotein levels (HDL), and fasting blood sugar levels (FBS); there existed a statistically significant difference between HDL and GAGS severity grading with $\mathrm{p}$-value $<0.05$, when compared to other variables (Table-4). Even though there was no statistically significant difference between WC, SBP, DBP, TG, FBS and GAGS severity grading, there was an increase in the mean scores of WC, SBP, DBP, FBS from mild to severe grading of GAGS. The triglyceride levels had decreased from mild to severe grading of GAGS. All these results constitute that the variables of metabolic syndrome had an impact on the severity of acne vulgaris (Table-4). Even though there was no statistically significant correlation between GAGS disease severity and metabolic syndrome criteria, there was positive correlation between GAGS disease severity and WC, SBP, DBP, FBS and there was negative correlation between GAGS disease severity and TG, HDL (Table-5).

Table 2: Characteristics of Acne Patients

\begin{tabular}{|c|c|}
\hline Variable & Findings \\
\hline Gender: Male/Female (\%) & $44(42.7 \%) / 59(57.3 \%)$ \\
\hline Age (years): Mean \pm SD & $38.5 \pm 11.22$ \\
\hline Age group: $\leq 25$ years $(\%) />25$ years $(\%)$ & $15(14.6 \%) / 88(85.4 \%)$ \\
\hline Waist circumference $(\mathrm{WC})$ in inches: Mean \pm SD & $35.0 \pm 3.80$ \\
\hline Systolic Blood Pressure (SBP) in mm Hg: Mean \pm SD & $124.6 \pm 12.18$ \\
\hline Diastolic Blood Pressure (DBP) in mm Hg: Mean \pm SD & $82.7 \pm 11.06$ \\
\hline Triglyceride (TG) in mg/dL: Mean + SD & $102.5 \pm 26.68$ \\
\hline High Density Lipoprotein (HDL) in mg/dL: Mean \pm SD & $44.3 \pm 5.40$ \\
\hline Fasting Blood Sugar (FBS) in mg/dL: Mean \pm SD & $119.5 \pm 27.71$ \\
\hline Global Acne Grading System (GAGS) score: Mean \pm SD & $21.4 \pm 9.29$ \\
\hline Diet: Vegetarian (\%) / Mixed (\%) & $13(12.6 \%) / 90(87.4 \%)$ \\
\hline Alcoholism: Present (\%) / Absent (\%) & $15(14.6 \%) / 88(85.4 \%)$ \\
\hline Smoking: Present $(\%) /$ Absent $(\%)$ & $19(18.4 \%) / 84(81.6 \%)$ \\
\hline Family history of Acne: Present (\%) / Absent (\%) & $72(69.9 \%) / 31(30.1 \%)$ \\
\hline Metabolic Syndrome (MS): Present (\%) / Absent (\%) & $54(52.4 \%) / 49(47.6 \%)$ \\
\hline GAGS-severity: Mild (\%) / Moderate (\%) / Severe (\%) & $45(43.7 \%) / 37(35.9 \%) / 21(20.4 \%)$ \\
\hline
\end{tabular}

Table 3: Association between Various Variables and Gags

\begin{tabular}{|c|c|c|c|c|c|c|c|c|c|c|}
\hline \multirow{3}{*}{\multicolumn{2}{|c|}{ Variable }} & \multicolumn{6}{|c|}{ Global Acne Grading System } & \multirow{3}{*}{$x_{0}^{2}$} & \multirow{2}{*}{\multicolumn{2}{|c|}{ df p-value }} \\
\hline & & \multicolumn{2}{|l|}{ Mild } & \multicolumn{2}{|c|}{ Moderate } & \multicolumn{2}{|l|}{ Severe } & & & \\
\hline & & Number of patients & $\%$ & Number of patients & $\%$ & Number of patients & $\%$ & & \multirow{2}{*}{2} & \multirow{3}{*}{0.0001} \\
\hline \multirow{2}{*}{ Metabolic syndrome } & Present & 12 & $22.2 \%$ & 31 & $57.4 \%$ & 11 & $20.4 \%$ & \multirow{2}{*}{\multicolumn{2}{|c|}{26.559}} & \\
\hline & Absent & 33 & $67.3 \%$ & 6 & $12.2 \%$ & 10 & $20.4 \%$ & & & \\
\hline \multirow{2}{*}{ Age group } & $\leq 25$ years & 10 & $66.7 \%$ & 2 & $13.3 \%$ & 3 & $20.0 \%$ & \multirow{2}{*}{4.617} & \multirow{2}{*}{2} & \multirow{2}{*}{0.099} \\
\hline & $>25$ years & 35 & $39.8 \%$ & 35 & $39.8 \%$ & 18 & $20.5 \%$ & & & \\
\hline \multirow{2}{*}{ Gender } & Male & 23 & $52.3 \%$ & 12 & $27.3 \%$ & 9 & $20.5 \%$ & \multirow{2}{*}{2.895} & \multirow{2}{*}{2} & \multirow{2}{*}{0.235} \\
\hline & Female & 22 & $37.3 \%$ & 25 & $42.4 \%$ & 12 & $20.3 \%$ & & & \\
\hline \multirow[b]{2}{*}{ Diet } & Vegetarian diet & 8 & $61.5 \%$ & 3 & $23.1 \%$ & 2 & $15.4 \%$ & \multirow[b]{2}{*}{1.951} & \multirow[b]{2}{*}{2} & \multirow{2}{*}{0.377} \\
\hline & Mixed diet & 37 & $41.1 \%$ & 34 & $37.8 \%$ & 19 & $21.1 \%$ & & & \\
\hline \multirow{2}{*}{ Alcoholism } & Present & 8 & $53.3 \%$ & 6 & $40.0 \%$ & 1 & $6.7 \%$ & \multirow{2}{*}{2.076} & \multirow{2}{*}{2} & \multirow{2}{*}{0.354} \\
\hline & Absent & 37 & $42.0 \%$ & 31 & $35.2 \%$ & 20 & $22.7 \%$ & & & \\
\hline \multirow[b]{2}{*}{ Smoking } & Present & 9 & $47.4 \%$ & 5 & $26.3 \%$ & 5 & $26.3 \%$ & \multirow{2}{*}{1.072} & \multirow[b]{2}{*}{2} & \multirow{2}{*}{0.585} \\
\hline & Absent & 36 & $42.9 \%$ & 32 & $38.1 \%$ & 16 & $19.0 \%$ & & & \\
\hline \multirow[b]{2}{*}{ Family history of acne } & Present & 31 & $43.1 \%$ & 24 & $33.3 \%$ & 17 & $23.6 \%$ & \multirow{2}{*}{1.687} & \multirow[b]{2}{*}{2} & \multirow{2}{*}{0.430} \\
\hline & Absent & 14 & $45.2 \%$ & 13 & $41.9 \%$ & 4 & $12.9 \%$ & & & \\
\hline
\end{tabular}


Table 4: Metabolic Syndrome In Relation To Gags

\begin{tabular}{|c|c|c|c|c|c|c|}
\hline Variable & GAGS & Mean & Std. Deviation & $\mathbf{F}$ & df & p-value \\
\hline \multirow{3}{*}{ WC } & Mild & 34.3189 & 4.38076 & \multirow{3}{*}{2.408} & \multirow{3}{*}{2} & \multirow{3}{*}{0.095} \\
\hline & Moderate & 36.1038 & 3.54706 & & & \\
\hline & Severe & 34.6919 & 2.35537 & & & \\
\hline \multirow{3}{*}{ SBP } & Mild & 123.6667 & 14.03729 & \multirow{3}{*}{0.696} & \multirow{3}{*}{2} & \multirow{3}{*}{0.501} \\
\hline & Moderate & 124.1892 & 12.10564 & & & \\
\hline & Severe & 127.3810 & 7.00340 & & & \\
\hline \multirow{3}{*}{ DBP } & Mild & 81.0667 & 10.50195 & \multirow{3}{*}{1.865} & \multirow{3}{*}{2} & \multirow{3}{*}{0.160} \\
\hline & Moderate & 82.7027 & 13.04877 & & & \\
\hline & Severe & 86.6667 & 7.30297 & & & \\
\hline \multirow{3}{*}{ TG } & Mild & 103.2667 & 27.62361 & \multirow{3}{*}{0.421} & \multirow{3}{*}{2} & \multirow{3}{*}{0.657} \\
\hline & Moderate & 104.4324 & 28.09759 & & & \\
\hline & Severe & 97.9048 & 22.42299 & & & \\
\hline \multirow{3}{*}{ HDL } & Mild & 45.6000 & 4.84487 & \multirow{3}{*}{3.853} & \multirow{3}{*}{2} & \multirow{3}{*}{0.024} \\
\hline & Moderate & 42.4865 & 5.93774 & & & \\
\hline & Severe & 45.1905 & 4.83342 & & & \\
\hline \multirow{3}{*}{ FBS } & Mild & 116.2000 & 29.35024 & \multirow{3}{*}{0.581} & \multirow{3}{*}{2} & \multirow{3}{*}{0.561} \\
\hline & Moderate & 121.6216 & 25.70490 & & & \\
\hline & Severe & 122.9048 & 28.05335 & & & \\
\hline
\end{tabular}

Table-5: Correlation between Gags Disease Severity and Characteristics of Patients

\begin{tabular}{|c|c|c|}
\hline Variable & $\mathbf{r} \wedge$ & p-value \\
\hline AGE & 0.15 & 0.117 \\
\hline WC & 0.14 & 0.148 \\
\hline SBP & 0.13 & 0.19 \\
\hline DBP & 0.16 & 0.087 \\
\hline TG & -0.04 & 0.689 \\
\hline HDL & -0.07 & 0.446 \\
\hline FBS & 0.04 & 0.656 \\
\hline r $\wedge$ - Pearson correlation & \multicolumn{2}{|l}{} \\
\hline
\end{tabular}

\section{Discussion}

Acne appears to be a widespread, complex skin disease that affects individuals of all age groups ${ }^{[14]}$. In the present study, as the age increased the chances of developing acne also increased, these results were similar to Law $\mathrm{M}$ et al. ${ }^{\text {[14] }}$ conclusion. Yang Y et al. ${ }^{[15]}$. in their study reported that females were more vulnerable to acne than males, these results were similar to present study findings. In the present study, there was no statistically significant association between GAGS disease severity and age, gender these results were similar to Rostami Mogaddam M et al. ${ }^{[16]}$. and Nagpal et al. ${ }^{[17]}$ results. Emiroğlu $\mathrm{N}$ et al. ${ }^{[3]}$ in their study stated that the relationship between diet and acne appears to be uncertain in recent years, these results were similar to present study findings that diet has no statistically significant association with acne severity.

In the present study, there was no statistically significant difference between GAGS disease severity groups and WC, SBP, DBP, TG, FBS; these results were similar to Nagpal et al. ${ }^{[17]}$ study. In the present study, there was a statistically significant difference between GAGS disease severity groups and HDL which was similar to Beigh and Jain et al. ${ }^{[18]}$ study.

In the present study, it was reported that there was no significant correlation between GAGS disease severity and metabolic syndrome criteria these results were in accordance with Balta et al. [19] study. The metabolic syndrome and the GAGS severity grading had an extreme statistically significant association in the present study. Ahmed GI et al. ${ }^{[20]}$. study results were similar to present study results.

\section{Conclusion}

There exists an association between acne vulgaris and metabolic syndrome. Reduction in HDL will have a significant increase in the acne vulgaris severity. All the variables of metabolic syndrome may have an impact on the severity of acne vulgaris, to generalize further clinical studies on a larger scale should be conducted.

Limitations: Results cannot be generalized as the sample size was small.

\section{Conflict of Interest: None to declare}

\section{Source of Funding: Nil}

\section{References}

1. Sharma RK, Dogra S, Singh A, Kanwar AJ. Epidemiological patterns of acne vulgaris among adolescents in North India: a cross-sectional study and brief review of literature. Indian Journal of Paediatric Dermatology 2017;18(3):196. (Last accessed on 25.09.2021)

2. Adityan B, Kumari R, Thappa D. Scoring systems in acne vulgaris. Indian Journal of Dermatology, Venereology and Leprology 2009;75(3):323. (Last accessed on 25.09.2021)

3. Emiroğlu N, Cengiz FP, Kemeriz F. Insulin resistance in severe acne vulgaris. Advances in Dermatology and Allergology/Postępy Dermatologii i Alergologii 2015;32(4):281. (Last accessed on 25.09.2021)

4. Kim MH, Ha IJ, Kim E, Kim K. Integrated targeted serum metabolomic profile and its association with gender, age, disease severity, and pattern identification in acne. PloS one 2020;15(1):e0228074. (Last accessed on 25.09.2021) 
5. Shah N, Shukla R, Chaudhari P, Patil S, Patil A, Nadkarni N, et al. Prevalence of acne vulgaris and its clinico-epidemiological pattern in adult patients: Results of a prospective, observational study. Journal of cosmetic dermatology. 2021 Mar 2. (Last accessed on 28.09.2021)

6. Durai PC, Nair DG. Acne vulgaris and quality of life among young adults in South India. Indian journal of dermatology 2015;60(1):33. (Last accessed on 28.09.2021)

7. Adityan B, Thappa D. Profile of acne vulgaris-A hospital-based study from South India. Indian Journal of Dermatology, Venereology and Leprology 2009;75(3):272. (Last accessed on 28.09.2021)

8. Kubba R, Bajaj AK, Thappa DM, Sharma R, Vedamurthy $\mathrm{M}$, Dhar $\mathrm{S}$, et al. Acne scars. Indian journal of dermatology, venereology and leprology 2009;75(S1):52-3. (Last accessed on 25.09.2021)

9. George RM, Sridharan R. Factors aggravating or precipitating acne in Indian adults: a hospital-based study of 110 cases. Indian journal of dermatology 2018;63(4):328. (Last accessed on 28.09.2021)

10. Goulden V, Clark SM, Cunliffe WJ. Post-adolescent acne: a review of clinical features. British journal of dermatology 1997;136(1):66-70. (Last accessed on 26.09.2021)

11. Khunger N, Kumar C. A clinico-epidemiological study of adult acne: is it different from adolescent acne? Indian journal of dermatology, venereology and leprology 2012;78(3):335. (Last accessed on 26.09.2021)

12. Kaur J. A comprehensive review on metabolic syndrome. Cardiology research and practice. 2014 Oct 2014. (Last accessed on 26.09.2021)

13. Huang PL. A comprehensive definition for metabolic syndrome. Disease models \& mechanisms 2009;2(56):231-7. (Last accessed on 26.09.2021)

14. Law MP, Chuh AA, Lee A, Molinari N. Acne prevalence and beyond: acne disability and its predictive factors among Chinese late adolescents in Hong Kong. Clinical and Experimental Dermatology: Clinical dermatology 2010;35(1):16-21. (Last accessed on 26.09.2021)

15. Yang YC, Cheng YW, Lai CS, Chen W. Prevalence of childhood acne, ephelides, warts, atopic dermatitis, psoriasis, alopecia areata and keloid in Kaohsiung County, Taiwan: a community-based clinical survey. Journal of the European Academy of Dermatology and Venereology 2007;21(5):643-9. (Last accessed on 26.09.2021)

16. Rostami Mogaddam M, Safavi Ardabili N, Maleki N, Soflaee M. Correlation between the severity and type of acne lesions with serum zinc levels in patients with acne vulgaris. BioMed research international. 2014. (Last accessed on 26.09.2021)

17. Nagpal M, De D, Handa S, Pal A, Sachdeva N. Insulin resistance and metabolic syndrome in young men with acne. JAMA dermatology 2016;152(4):399-404. (Last accessed on 26.09.2021)

18. Beigh SH, Jain S. Prevalence of metabolic syndrome and gender differences. Bioinformation 2012;8(13):613. (Last accessed on 26.09.2021)

19. Balta I, Ekiz O, Ozuguz P, Ustun I, Karaca S, Dogruk Kacar S, et al. Insulin resistance in patients with post-adolescent acne. International journal of dermatology 2015;54(6):662-6. (Last accessed on 26.09.2021)

20. Ahmed GI, Yousef AE, Salah El-Din E. Evaluation of the Association between Acne Vulgaris and Metabolic Syndrome in Adolescents at Zagazig University Hospitals. The Egyptian Journal of Hospital Medicine 2020;81(3):1628-33. (Last accessed on 26.09.2021) 